Volume $50 \cdot$ Number $8 \cdot 2013$

\title{
FATE OF PROSTHETICS RESEARCH AS THE BULLETIN OF PROSTHETICS RESEARCH HAS BECOME THE JOURNAL OF REHABILITATION RESEARCH AND DEVELOPMENT
}

\section{T. WALLEY WILLIAMS III, MA}

T/he Department of Veterans Affairs (VA) has a continuous history of publishing the journal now called the Journal of Rehabilitation Research and Development (JRRD). While the first issues were published by the Prosthetic and Sensory Aids Service, it took 3 years before Eugene Murphy published an editorial reminding the readers that sensory aids were supposed to be part of the mix. That issue, Bulletin of Prosthetics Research (BPR) 10-2, had five articles on reading machines and other sensory aids. In 1978, a subtitle of "Rehabilitative Engineering Research and Development" was added to the title page because it became apparent that the journal needed to expand the way it was serving veterans. Finally in 1983 , the format and title were changed to the present JRRD.

Today, JRRD addresses a wide range of research on rehabilitation. The journal covers every rehabilita- tive subject of relevance to American veterans. This coverage includes posttraumatic stress disorder and other newly recognized fields of warrelated injury, as well as the needs of elderly veterans both at home and in VA hospitals. Articles on rehabilitation are submitted from all parts of the world. There are now 13 associate editors covering the areas of greatest interest in rehabilitation in general, with particular applicability to the veteran population. The VA system vies with Britain's National Health Service for being the world's largest integrated health organization. The large population served by the VA in the United States has allowed it to fund and report on topics that require large, well-defined populations.

Does the journal still address the orthotic and prosthetic (0\&P) needs of veterans? Yes, and in greater depth than ever. The O\&P field is huge on a worldwide basis, but having enough subjects at hand locally to do meaningful studies is still a problem. Fortunately, the VA is sufficiently integrated that multi-institution studies can be done to obtain a greater number of subjects. In addition, the journal reports on the latest developments in the O\&P field when the papers submitted show clinical relevance. When these papers appear, they have been peer reviewed and can be sited in other publications. O\&P practitioners everywhere benefit from immediate free access to the journal. This aspect is most important in the developing world, where funding is scarce but the need to treat landmine amputations and other conflict-related injuries is the greatest. 